\title{
Identidade e pertencimento: a dinâmica social de um grupo de mulheres no Vale do Taquari, Rio Grande do Sul
}

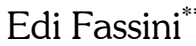 \\ Neli Galarce Machado*** \\ Glauco Schultz***:
}

\section{Resumo}

O artigo discute os resultados da pesquisa que enfoca as percepções de um grupo de mulheres que formam a rede social conhecida como "Clube de Mães". Essa rede é de ocorrência comum em toda a região do Vale do rio Taquari. A investigação foi realizada a partir de uma perspectiva etnográfica, priorizando a convivência com o grupo nas suas experiências coletivas. Foram realizadas entrevistas com todas as integrantes do grupo em suas residências. As entrevistas partiram de questões abertas. Dada a complexidade que envolve temática tão subjetiva, o trabalho apresenta um arcabouço teórico acerca da conceituação de identidade, cultura e pertencimento, como ancoragem para a análise. O texto apresenta descrição densa, envolvendo situações cotidianas, cujos sentidos são apreendidos pelo pesquisador que as narra e interpreta a partir de sua experiência e do contexto local-cultural dos investigados.

Palauras-chave: Identidade, Percepção, Representação, Cultura, Pertencimento.

\footnotetext{
" Recebido para publicação em 4 de maio de 2011, aceito em 26 de setembro de 2012.

** Mestre pelo Programa em Ambiente e Desenvolvimento, Centro Universitário Univates, professora da rede municipal de Imigrante. edif@univates.br

**** Professora do Programa em Ambiente e Desenvolvimento, Centro Universitário Univates.ngalarce@univates.br ou nelitgm@terra.com.br

***** Professor do Programa em Ambiente e Desenvolvimento, Centro Universitário Univates.
}

cadernos pagu (41), julho-dezembro de 2013:405-433. 
Identity and Belonging: The Social Dynamics of a Women Group at Taquari Valley, State of Rio Grande do Sul

\begin{abstract}
The paper discusses the results of research that focuses on the perceptions of a women group who form the social network known as Mothers Club. This network is a common occurrence throughout the Taquari river's Valley region. The research was conducted from an ethnographic perspective, prioritizing the coexistence with the group on their collective experiences. Interviews were conducted with all members of the group and in their homes. The interviews began from open questions. According to the complexity that involves so subjective thematic, the paper presents a theoretical framework about the conception of identity, culture and belonging, such as anchorage for analysis. The text presents thick description, involving daily situations, whose senses are apprehended by the researcher who narrates and interprets from his experience and the cultural-local context of investigated.
\end{abstract}

Key Words: Identity, Perception, Representation, Culture, Belonging. 


\section{Introdução}

A discussão que segue retoma a abordagem de alguns autores acerca dos temas identidade, cultura e pertencimento. $\mathrm{O}$ objetivo é apresentar o que esses conceitos significam $e$ representam, de forma interconectada, e principalmente demonstrar o reflexo dessas percepções na vida dos indivíduos. Esse é um dos aspectos investigados e detalhados na dissertação "Identidade Individual e Coletiva: Percepções e Representações das Mulheres na sua participação em uma Rede Social" (Fassini, 2010), realizado no mestrado do Programa de Pós-Graduação em Ambiente e Desenvolvimento da Univates, Centro Universitário de Lajeado, Rio Grande do Sul.

Observar o comportamento de outras pessoas é procedimento natural para a maioria dos pesquisadores. Maturana (2006) afirma que os cientistas são pessoas que têm prazer em explicar como as coisas são e como acontecem; para isso, empreendem estudos, mergulham em pesquisas, sistematizam observações, articulam interações. A observação de comportamentos humanos e seus problemas singulares motivaram este trabalho. A ideia surgiu a partir de uma situação curiosa, na observação de um grupo de mulheres em diferentes situações de vida coletiva. Em eventos denominados chás de clubes de mães, observamos mulheres alegres, desinibidas, muito participativas $e$ extrovertidas. Noutras programações comunitárias, essas mulheres apresentavam comportamento muito diverso: pouco envolvimento, introspecção, atitudes contidas, parecendo alheias ao movimento em seu entorno.

Foi a partir dessa percepção que a proposta de uma investigação na vida de um grupo de mulheres organizadas em uma rede social, informalmente conhecida como "Clube de Mães" e sediada num pequeno município do interior do Rio Grande do Sul (região do Vale do Taquari), chamado Imigrante, tornou-se nosso alvo. Essa temática é desafiadora no sentido de buscar compreender o processo de construção da identidade humana, 
partindo da observação do comportamento e da investigação dos porquês das ações cotidianas desse grupo de mulheres.

O grupo investigado é formado por 11 mulheres, cuja faixa etária varia de 46 a 84 anos. Os trabalhos domésticos e aqueles ligados à agricultura ocupam parte do grupo, outra parte são funcionárias de uma indústria de confecção local. Os dados relativos à escolaridade variam da semi-alfabetização até a conclusão do ensino médio. Com relação aos níveis socioeconômicos, todas moram em casa própria e dispõem de condições consideradas satisfatórias; nenhuma de suas famílias está integrada a programas sociais de combate à pobreza, já que têm renda que ultrapassa os limites mínimos estabelecidos. Nos aspectos culturais, o grupo reúne uma variedade de etnias, línguas, trabalhos e credos religiosos.

Vários autores contribuíram para esclarecer pressupostos $e$ aprofundar entendimentos. A leitura de Clifford Geertz (1989) nos inspirou no caminho da pesquisa etnográfica, com as características que o autor define como descrição densa, sendo que

...praticar a etnografia é estabelecer relações, selecionar informantes, transcrever textos, levantar genealogias, mapear campos, manter um diário e assim por diante (Geertz, 1989:4).

Buscamos compreender $e$ interpretar a forma de vida do grupo de mulheres selecionadas, entrevistando-as, observando rituais, elos de parentesco, sua história de vida individual e do grupo, projetos presentes e futuros, registrando suas falas $e$ comportamentos em diferentes momentos. Tudo isso desencadeou inúmeras indagações, reflexões e a necessidade de novas leituras. Oportunizou-nos a ciência de saberes e práticas cotidianas de pessoas com diferentes percepções sobre a vida.

A etnografia propõe um mergulho na vida e cultura do objeto pesquisado para sua descrição. Mas, além disso, a convivência que se estabelece entre pesquisadores e pesquisados 
propõe a compreensão e a interpretação dos comportamentos, rotinas, crenças e relação entre os participantes do trabalho. É nesse imenso oceano que mergulhamos.

\section{Método de pesquisa}

Segundo Gil (2006:17), "pode-se definir pesquisa como o procedimento racional e sistemático que tem como objetivo proporcionar respostas aos problemas que são propostos". Com este trabalho, buscamos compreender os significados, e a partir de quais representações são eles construídos, da participação de um grupo de mulheres em uma rede social intitulada "Clube de Mães".

Analisamos o significado de seus discursos e de suas práticas; acompanhamos o desenvolvimento de reuniões do grupo; entrevistamos individualmente suas integrantes a partir de questões abertas; observamos o comportamento dessas mulheres em diferentes situações sociais; ouvimos opiniões de pessoas próximas a elas, mas não integrantes do grupo; convivemos com o grupo em diferentes momentos.

Thompson (1998:254) nos orientou para nossa postura nos momentos de entrevista. Segundo o autor, o entrevistador deve demonstrar "interesse e respeito pelos outros como pessoas $e$ flexibilidade nas reações em relação a eles; capacidade de demonstrar compreensão e simpatia pela opinião deles, e, acima de tudo, disposição para ficar calado e escutar". Buscamos fazer perguntas simples e diretas (e não diretivas), empregando termos cotidianos comumente utilizados na comunidade, com o objetivo de encorajá-las a falar sobre suas vidas e a vida do grupo, seus fazeres e seus projetos comuns.

Toda fonte histórica derivada da percepção humana é subjetiva, mas apenas a fonte oral permite-nos desafiar essa subjetividade: descolar as camadas da memória, cavar fundo em suas sombras, na expectativa de atingir a verdade oculta (Thompson, 1998:197). As percepções e significações que cada uma das mulheres referiu para sua participação no grupo demandaram 
"cavar fundo" em sua subjetividade, pensar sobre o cotidiano, fazeres, relações e emoções. Estabelecer essa reflexão foi um desafio para elas, pois essa é uma conversa que as pessoas não costumam fazer.

Cientes de que o ser humano se expressa não somente por palavras, procuramos observar o comportamento, os gestos, as expressões de dúvidas e de emoções nem sempre traduzidas nas palavras. Buscamos essa atenção e "escuta" no acompanhamento das reuniões do grupo $e$ em outros eventos em que encontrávamos integrantes do clube de mães. Prestamos atenção ao modo de cada uma falar de si mesma, ao que dava destaque, o que deixava de lado, as palavras que escolhia. Púnhamos atenção às minúcias, alertados por Thompson (1996) de que os detalhes são importantes para a compreensão de qualquer entrevista, especialmente na interpretação etnográfica, em que se tornam o texto fundamental.

Minayo contribui conosco na atenção a esse aspecto:

[...] qualquer discurso teórico não é a revelação total da realidade, é a realização de um real possível ao sujeito, sob condições histórico-sociais dadas: o objeto construído anuncia e denuncia o sujeito que a constrói: ela é a exteriorização de sua interioridade, do seu tempo, do seu meio, de suas questões, de sua inserção de classe (Minayo, 1996:250).

A decisão de lançar mão de diferentes instrumentos para reunir informações sobre o objeto de pesquisa foi motivada pela curiosidade de experimentar a realização de registros etnográficos. Fino (2007) define a etnografia como a descrição da cultura em que o pesquisador mergulha. E não só a descrição, mas a busca da compreensão $e$ interpretação das situações que envolvem os comportamentos, rotinas, crenças e relações entre os dados e entre os participantes do trabalho de pesquisa, não somente os entrevistados. 
Durante a pesquisa, fizemos imersão na vida do grupo, observando falas, rotinas, costumes; dialogando e provocando a evocação dos porquês de fazeres; buscando captar significados nos gestos, nas expressões, nos tons de voz. Foram feitas visitas às residências dessas mulheres para as entrevistas individuais em datas programadas; e participamos de reuniões do grupo com o intuito de observar o comportamento das integrantes; dialogamos com integrantes do grupo durante eventos culturais na comunidade; coletamos informações acerca do histórico do grupo a partir do livro de atas de reuniões.

A tarefa de revelar os significados das informações colhidas exigiu esforço, dedicação de tempo e leituras de embasamento teórico que serviram de referência para formular interpretações. Fazer a descrição narrativa de um período de convivência com o grupo, cientes da relação estabelecida entre quem investiga $e$ quem é investigado, revelou-se realmente uma tarefa substanciosa. A tentativa de manter a imparcialidade frente às situações de convívio e de opinião, especialmente as de conflito entre os sujeitos da pesquisa, esteve sempre presente, evitando direcionar falas e ações dos investigados. Porém, conforme Fino (2007), a subjetividade do investigador entra no jogo da interpretação; quanto mais imerso na vida da comunidade, mais se amplia a possibilidade de compreensão dos porquês de suas falas, de sua forma de agir e de se relacionar com o ambiente.

Para facilitar a compreensão, iniciamos situando sujeitos pesquisados, caracterizando a aldeia onde convivemos para construir esse trabalho.

\section{Contextualização sócio-histórica do território}

Imigrante é um pequeno e jovem município localizado no Vale do Taquari, Rio Grande do Sul. Seu território se compõe de $76 \mathrm{~km}^{2}$ e sua população se constitui de 3.025 habitantes, de acordo com a contagem da população feita pelo IBGE, em 2010. A formação do município de Imigrante aconteceu a partir de um 
movimento popular dirigido por lideranças locais, embasadas no entendimento que o território sofria pela desatenção das autoridades municipais $e$ as pessoas dali se consideravam abandonadas, sem o atendimento a serviços básicos de saúde e de infraestrutura de comunicação e estradas. Um plebiscito ocorrido em 10 de abril de 1988 consubstanciou a vontade popular, com o resultado de $80 \%$ dos votantes optando pelo "sim" à formação do município.

Hessel (1998) explica que a definição do nome "Imigrante" aconteceu após longa discussão das lideranças do movimento pela emancipação, que entenderam ser a forma de homenagear os primeiros habitantes do território, imigrantes provindos da Europa, principalmente da Alemanha e Itália, cuja descendência forma, atualmente, grande parte da população local.

Sinais de cultivo à memória dos antepassados e de fomento à cultura europeia trazida pelos colonizadores imigrantes são percebidos no cotidiano da população. A existência de grupos de danças alemãs e italianas, de canto-coral e grupos instrumentais de formação e repertório típicos são sinais disso. Corrobora essa afirmativa a inserção no currículo escolar da rede municipal de componentes curriculares de língua italiana e língua alemã, como alternativa de escolha da família. Ainda, o calendário anual de eventos do município concentra atividades e eventos muito variados, emblemáticos da diversidade cultural.

As duas comunidades urbanas, originadas dos antigos distritos, mantêm características que as diferenciam uma da outra: os moradores de Daltro Filho cultivam costumes de origem italiana e católica; a sede do município, Arroio da Seca, possui marcas características da cultura de origem alemã e luterana.

Quanto à economia, dados obtidos junto à Secretaria de Administração e Fazenda do Município, mostram que Imigrante sobrevive do tripé agropecuária, indústria e serviços, variação que lhe oferece um equilíbrio econômico-social interessante. Produção de aves, suínos e leite são os itens mais significativos da produção primária. Metalurgia, produtos químicos de limpeza, confecções, 
laticínios e derivados da madeira, compõem a indústria de transformação.

\section{A rede social "Clube de Mães"}

A expressão "clube de mães" é encontrada em notícias de divulgação de encontros e campanhas, geralmente de cunho solidário, em muitos veículos de comunicação. Esses grupos existem em diferentes estados brasileiros. $\mathrm{O}$ teor das notícias leva-nos a inferir que sua atuação está geralmente associada à amenização de problemas da comunidade local, com ações pontuais de participação cidadã e, às vezes, com atividades que visam a geração de renda complementar para as integrantes dos grupos.

As primeiras investidas desta pesquisa acerca do assunto aconteceram junto ao escritório EMATER - Empresa de Assistência Técnica e Extensão Rural local, já que a funcionária que detém o cargo de extensionista rural é quem faz a coordenação geral desse trabalho com mulheres. Tomamos conhecimento que cada uma das comunidades rurais $e$ as duas comunidades urbanas de Imigrante têm pelo menos um "Clube de Mães". Esses grupos mantêm uma rotina de encontro mensal de trabalho com a coordenação geral. Além disso, promovem encontros festivos aos sábados à tarde, dos quais participam representantes de outros Clubes de Mães da região.

A intensa movimentação de vans e ônibus nas tardes de sábado transportando grupos de mulheres para participarem de "Chá de Clubes de Mães" causou-nos surpresa e daí nos surgiram perguntas acerca da mudança de rotinas dentro das famílias promovida por esse movimento. Afinal, pensamos, um turno semanal tem agenda fixa para essas mulheres ligadas ao lar e ao trabalho na agricultura ou funcionárias de indústrias locais, segundo a informação da coordenadora.

A primeira conversa com a coordenadora foi de explicações sobre a proposta de pesquisa. Ela nos recebeu com certa desconfiança, como se não acreditasse em sua importância 
enquanto sujeito histórico. Explicamos nossos objetivos e ela ficou confortável ao passo que a conversa se desenvolvia. Essa primeira abordagem despertou em nós várias reflexões e suposições: novos aprendizados, decorrentes da socialização de vivências e saberes entre as integrantes dessa rede social, possivelmente refletiriam em mudanças no comportamento individual e na vida familiar.

Elas convivem com outras mulheres nos encontros festivos, cujo território se expande para a região, pois os grupos mantêm vínculos com clubes de mães de outros municípios. Isso pode gerar mudanças no seu modo de ser e de apreender o mundo. Ainda, o desempenho de funções na organização do grupo, diferentes das exercidas na vida pessoal - inclui-se a família e o trabalho, desencadeia mudanças na sua forma de ser e perceberse a si mesma e aos outros? Autoestima, relações interpessoais, percepções acerca da vida, da sociedade, do ambiente, entre outros aspectos, sofrem influência da experiência de fazer parte do Clube de Mães?

Dentre os 12 grupos de mulheres existentes no município de Imigrante, optamos por nos aproximarmos do Clube de Mães Blumenstrauss do bairro Daltro Filho, comunidade que apresenta uma diversidade étnico-cultural maior, e é um grupo com poucas integrantes, o que permitiu interessantes conversas individuais com todas elas.

\section{Blumenstrauss - a historicidade do grupo}

A partir da conversa com a coordenadora geral, soubemos da agenda de reuniões do grupo selecionado. A apresentação dos pesquisadores e do projeto foi o início e a partir daí negociou-se a possibilidade de convívio para a realização do trabalho. Já credenciados pela coordenadora geral, nossa proposta foi aceita "com muita honra", segundo elas. Imediata também foi a liberação do livro de atas, que contém informações sobre o funcionamento do grupo desde a sua fundação, com as que seguem. 
Há treze anos, um grupo de mulheres de uma localidade oficialmente urbana, mas com característica de vida rural, se reuniu no dia 13 de agosto na casa de uma delas, com a finalidade de iniciar um "clube de mulheres", conforme ata da reunião. Nesse documento consta que a coordenadora do trabalho, funcionária da EMATER, explicou como deve funcionar o trabalho para o bom andamento do grupo: "procurar sempre compreender a outra, isto é, ver sempre as qualidades e aceitar os defeitos e, principalmente, sermos sempre sinceras". Desde os primeiros registros de reuniões, encontram-se referências ao aprendizado e à socialização de informações e ideias acerca de práticas gastronômicas, cuidados com a saúde preventiva $e$ curativa, economia doméstica, cuidados ambientais e trabalhos artesanais, entre outros.

O grupo começou com treze mulheres, onze delas mães. Já na primeira reunião, combinaram que os encontros seriam mensais e que, em forma de rodízio, cada uma das integrantes seria anfitriã. Assim, o grupo não teria local fixo para reunir-se. E ainda na mesma tarde de agosto de 1996, escolheram uma representante, enquanto não fosse votada uma diretoria $e$ combinaram "uma colaboração das componentes para as primeiras despesas", mas não há registro acerca do que comporia essas despesas. O nome Blumenstrauss (Buquê de Flores) foi sugestão de uma das "sócias" e acolhida porque teve "votação favorável do grupo". Grupo de Senhoras, Clube de Mulheres, Grupo Blumenstrauss - essas são as formas registradas em atas identificando o grupo. Em agosto de 1999, pela primeira vez, a organização está referida como Clube de Mães Blumenstrauss e nada consta como explicação para isso.

As atas seguintes revelam a regularidade de reuniões, conforme a proposta: encontros mensais, sempre noutra casa $e$ com média de 10 presenças nos primeiros 8 anos. Os registros, apesar das dificuldades no uso da língua escrita, evidenciam cuidado e zelo para escrever sobre o assunto da palestra ou prática socializada. Várias atas, relatam rotinas das reuniões que se 
iniciam com uma oração ou canto, seguindo-se a leitura da ata da reunião anterior, depois palestra, associada ou não a uma prática gastronômica, de trabalho artesanal ou feitura de chá, pomada, ou remédio caseiro à base de "ervas medicinais" (este último assunto é mencionado seguidamente nos registros).

Conforme a habilidade da escriba, função que se alterna entre as sócias que "levam jeito para escrever", os registros são mais completos ou apenas apontam local, data, assunto tratado $e$ presenças, reveladas pelas assinaturas. Em alguns períodos as reuniões se realizaram bimestralmente, não havendo explicação escrita para a mudança de periodicidade. Exceção expressa consta na ata da reunião de dezembro de 1998, quando está explicado um período em que o grupo não teve reuniões, durante a licençamaternidade da profissional ligada à EMATER, que representa o elo entre o Blumenstrauss e outros grupos congêneres do Município de Imigrante, e que, junto com a diretoria eleita, programa os assuntos das reunióes.

Muito interessante é a forma como os registros anunciam o ingresso de novas integrantes: "com muita honra recebemos as novas sócias" e a seguir são nomeadas. Da mesma forma, são referidas a saída de alguma integrante, cuja desistência é comunicada às demais em reunião, pessoalmente ou por alguém da diretoria.

Em nenhum registro consta a motivação para a saída, contudo, a mudança de residência para outra cidade $e$ impossibilidade de participação nas reuniões por motivo de trabalho seriam razões plausíveis para alguns afastamentos. Algumas sócias entraram e saíram do grupo algumas vezes, mesmo continuando a residir no mesmo local. A relação entre duas informações - registros de ingresso de novas sócias e o nome da presidente do grupo no período (cargo renovado a cada ano em processo eletivo) - apontam para a hipótese do carisma agregador de algumas líderes; coincidência ou não, em gestões diferentes de uma mesma presidente, acontecem ingressos de novas sócias. 
As participantes são chamadas de sócias desde o primeiro encontro, ocasião em que já é mencionada a necessidade de colaboração de cada integrante para despesas do grupo. Em registros de reuniões subsequentes há menção acerca de rifa, com a finalidade de "formar caixa para o clube". Em data posterior consta em registro de ata que o grupo decidiu por definir uma contribuição mensal das integrantes, quando combinam uma taxa que é coletada a cada reunião.

Infere-se, acompanhando as informações das atas, que os recursos financeiros do grupo são utilizados para o custeio de locomoção das integrantes para os "chás de sábados à tarde", eventos de encontro e confraternização de vários grupos similares, oriundos de diversos municípios vizinhos. Esses encontros chamados Chá dos Clubes de Mães sempre têm a organização sob a responsabilidade de um grupo, e a programação consta de recepção aos visitantes, várias atrações de entretenimento $e$ integração, como brincadeiras, dança, exposição e venda de produtos artesanais e o momento gastronômico: chá ou café e grande variedade de pratos doces e salgados, os quais têm alguma variação conforme a cultura local.

Esse evento, que cada grupo organiza uma vez por ano, representa a maior entrada anual de recursos financeiros para o grupo promotor. Infere-se que o custeio pelo caixa coletivo das despesas para participação nesses chás é a forma de estimular a maior participação das sócias nessas saídas de intercâmbio, porque "temos a obrigação de colaborar com os outros para que venham no nosso chá", como consta em uma das atas de reunião.

\section{Diversidade de discussões e aprendizados}

As reuniões do grupo acontecem uma vez por mês (em alguns períodos, em intervalos maiores), tendo como local a casa de uma das participantes, em forma de rodízio; após uma mensagem, canto ou oração inicial, acontece um momento que os 
registros apontam como palestra, cuja responsabilidade está a cargo da profissional vinculada à EMATER.

Durante as reuniões do grupo são tratados assuntos de importância para o bem-estar da família e da comunidade. Alguns dos temas que constam nas atas são: cuidados básicos com relação à saúde, especialmente higiene e alimentação saudável; estudo acerca de várias doenças e formas de prevenir-se delas; propriedades e usos de ervas medicinais, com preparo de chás, pomadas e remédios caseiros; noções de economia doméstica, acompanhadas de preparo de produtos de uso comum nas famílias, aproveitando o que normalmente seria descartado, como por exemplo, sabão à base de gorduras residuais de uso doméstico.

Temas ligados à educação ambiental têm registros seguidos, dentre eles os cuidados com a água, tanto com relação à importância do consumo diário de "água pura", quanto ao zelo para não desperdiçá-la nas tarefas domésticas. O aproveitamento de cascas, talos e outras partes de vegetais, comumente não consideradas importantes e por isso descartadas, é apontado em registros de práticas gastronômicas experienciadas nas tardes de encontros, assim como o alerta para cuidados no manuseio de inseticidas e antipragas das lavouras. $\mathrm{O}$ aproveitamento de frutas $e$ legumes de produção sazonal em forma de conservas tem várias referências em atas.

A insistência com que se encontram apontamentos sobre uso de ervas medicinais, chás, pomadas e outros remédios caseiros denota a importância dada à coordenadora do trabalho a esse tema, havendo várias referências sobre relatos de sua participação em cursos afins. Infere-se que há interesse do grupo nesses estudos, haja vista a retomada de tempos em tempos, sobre preparo de produtos, envasamento e divisão entre as integrantes.

As práticas gastronômicas são bem variadas, compondo-se de pratos doces e salgados, mas tendo a preocupação de serem saudáveis. Diminuição de quantidades de sal e gorduras, assim como a substituição o quanto possível do açúcar branco pelo mel, melado e açúcar mascavo. A par dos efeitos do sal, açúcar branco 
e gorduras na saúde, as mulheres "botam a mão na massa" e preparam, sob a coordenação da instrutora, pratos saudáveis que são saboreados ao final das reuniões.

Não são poucas as referências sobre socialização de informações ou combinações de programações futuras, ou discussões sobre assuntos diversos, "enquanto o bolo assava" ou "aproveitando o tempo do creme esfriar". A medição da pressão arterial passou a ser prática nas reuniões, após a decisão tomada em grupo, em agosto de 1999, de adquirir um "aparelho de medir pressão", o qual é manuseado por uma integrante que recebeu treinamento para tal.

Escritos sobre práticas de trabalhos artesanais nas reuniões do grupo referem uso de materiais muito simples, como por exemplo, jornais velhos cujas folhas são enroladas, formando cordas de espessuras diversas, as quais são amarradas ou coladas, na construção de chapéus, fruteiras e outros utensílios de uso doméstico. Trabalhos envolvendo agulhas, linhas e tecidos são bastante frequentes e se mantêm no cotidiano do grupo durante todo o período de sua existência. Constatamos que em alguns períodos esses trabalhos dão lugar a uma novidade sugerida por alguém do grupo que aprendeu a lidar com novo material $e$ socializa isso com as colegas, por exemplo, pinturas. Depois voltam as referências às linhas, às agulhas, aos tecidos.

Há poucos registros sobre discussões do grupo durante ou após as palestras. Contudo, na reunião em que o assunto foi menopausa, há clara referência à conversa entre as integrantes que "já estão nessa fase"; registro semelhante encontra-se sobrea reunião em que o tema depressão foi abordado, quando é mencionada uma conversa "sobre como ajudar uma pessoa que se sente deprimida". Noutra reunião, a palestrante, muitas vezes referida como "a extensionista da EMATER", desenvolveu o tema "triglicerídeos", e então o registro assim aponta: "no nosso grupo só uma pessoa tem esse problema de saúde".

Os nomes das integrantes revelam uma rica diversidade de origem. As descendentes de alemães $e$ as descendentes de 
italianos representam cada facção, mais de um terço do grupo. Os nomes "Rodrigues" e "dos Santos", que revelam origem diversa, se restringem a duas familias. E resultantes de casamentos, acontecem novas mesclas culturais, porque mulheres de origem germânica são casadas com descendentes de italianos e assim por diante.

Ao pensarmos sobre as origens e os rótulos que surgem em função delas, nos vem à mente a questão da definição de um grupo étnico. Ocorre a ideia de que o sobrenome e os hábitos determinariam o pertencimento étnico de um sujeito a um grupo. Porém, para o antropólogo escandinavo Fredrik Barth (1998), as manifestações culturais não definem o grupo étnico, mas são uma produção dele. Corremos o risco de nos equivocar ao analisarmos o grupo a partir de elementos de sua cultura aparente e definir sua ligação a algum grupo social apenas por meio de sua observação estática, já que não é apenas a forma que o define. O que define um grupo étnico é um universo de simbologia e identidade (Barth, 1998:194).

Nesse grupo chamado Clube de Mães, ocorre a distinção entre as mulheres de origem italiana, alemã e outras, com um um turno de intensa convivência entre elas pelo menos uma vez ao mês. Essa pode ser a ocasião em que, confrontadas subjetivamente com outras maneiras de ser (descendência italiana, alemã ou outra), são repensadas suas próprias características que lhes distinguem em seu meio e que lhes atribuem uma identidade e um pertencimento ao grupo.

Constatamos rica convivência de uma diversidade étnica que mescla hábitos e costumes, valores e rotinas de trabalho $e$ vida, educação e rituais religiosos. Essa mescla profundamente carregada de simbologia pode servir como um terreno fértil para a compreensão, por cada uma das mulheres do grupo, de sua própria identidade perante elas mesmas e suas comunidades. 


\section{Trajetórias e historicidade das mulheres do Blumenstrauss}

Quem está e atua na história faz constantemente a experiência e que nada retorna. Reconhecer o que é não quer dizer aqui conhecer o que há num momento, mas perceber os limites dentro dos quais ainda há possibilidade de futuro para as expectativas e os planos: ou mais fundamentalmente, que toda expectativa $e$ toda planificação dos seres finitos é, por sua vez, finita e limitada. A verdadeira experiência é assim, a experiência da própria historicidade (Gadamer, 1998:527-528).

Situados na vida do grupo, a partir da leitura dos registros documentais e do acompanhamento de algumas reuniões do Blumenstrauss, optamos por reunir as informações colhidas durante as entrevistas individuais com as integrantes do grupo. Os textos que seguem são construções a partir do que ouvimos das entrevistadas associados ao que inferimos das escutas e das observações desses sujeitos em diferentes momentos em que foram alvo da nossa atenção, no período de agosto de 2009 a janeiro de 2010. O que segue foi construído na incansável busca de experienciar o que Geertz (1989) chama de descrição densa.

De início, tivemos dificuldade para efetivar algumas entrevistas, geralmente por situações externas à vontade dos diretamente envolvidos, como a chegada de uma visita inesperada ou o insistente toque do telefone na casa da entrevistada. Aconteceram adiamentos de entrevistas marcadas, por conta de eventos inusitados, como o falecimento de morador das proximidades ou de parentes, situações, essas, que demandam natural envolvimento das pessoas na comunidade pesquisada.

Não sentimos qualquer resistência à nossa presença nos encontros do grupo, tampouco com relação às visitas às residências para conversar individualmente com as mulheres. Entendemos que a negociação feita no início do trabalho foi efetiva para nos tornar familiar e assim ficou estabelecida a necessária confiança para nossas conversas individuais. 
As entrevistas foram apenas orientadas por questões abertas propostas por nós, após o tempo necessário para um preâmbulo que envolvia as flores do jardim, as crianças ou os cachorros que nos recebiam nas imediações da casa, ou as lindas peças artesanais que compunham o ambiente interno da residência. As conversas exigiram um tempo maior do que inicialmente imaginávamos, justamente porque buscamos construir um clima de tranquilidade e confiança para direcionar a temática, e então propondo, por exemplo: "conte-nos um pouco de sua vida."; "o que significa para você participar do clube de mães?"; "o que tem de bom em participar do clube de mães?"; "existem dificuldades na vida do grupo?"; "por que, mesmo, você integra o Blumenstrauss?"

A partir das respostas, puxávamos fio para a descoberta de novas apreensões e entendimentos. Algumas discorriam sobre vida, família, trabalho, angústias, alegrias, tarefas compartilhadas, sem necessidade de indagações. Com outras, a conversa, de fato, precisava ser incentivada a partir de algumas perguntas, então, tomávamos o cuidado de formulá-las com linguagem muito simples e sem direcionar as respostas, seguindo as orientações de Thompson (1996).

Uma constatação rápida e, em nossa percepção, interessante: a narrativa dos fatos da vida era-lhes tarefa muito fácil, discorriam naturalmente sobre situações vividas, como se essa resposta já estivesse pronta e, à medida que sentiam nosso interesse em ouvi-las, ampliavam os detalhes, puxavam da memória novas situações. Entretanto, indagações acerca do grupo, importância, dificuldades na convivência, etc., demandavam alguma reflexão, elaboração cuidadosa da resposta.

\section{Complexa construção etnográfica: apreensões e interpretações do ouvido, visto, percebido e vivido no Blumenstrauss}

$\mathrm{Na}$ constatação da rica diversidade da vida das mulheres que compõem o Blumenstrauss, nos surpreendemos com tantas 
semelhanças entre as que moram em área urbana $e$ as oriundas de área rural. Bosi (1987) constatou que a mulher camponesa identificava-se como inferior à mulher urbana. Aparência pessoal, educação, poder de consumo e práticas culturais e morais corroboravam esse entendimento. Neste trabalho, apesar de não termos abordado a questão diretamente, em nenhum momento percebemos referência a isso como algo importante para elas. $\mathrm{O}$ contexto de vida de quem reside na área urbana e de quem reside na área rural é muito parecido: as mulheres que trabalham na indústria têm, junto à sua residência, mesmo que em área urbana, um terreno onde a família cultiva horta, jardim com árvores $e$ flores e, na maioria das vezes, alguns animais de pequeno porte. As mulheres ligadas ao trabalho da agricultura e que residem em zona rural mantêm padrões de conforto, móveis, eletrodomésticos, carro, telefone e computador, entre outros itens, de forma similar às residências urbanas.

Silveira (2001), num estudo que envolveu as construções simbólicas de sujeitos do campo e da cidade, enfoca a uniformização da vida e costumes que os meios de comunicação, especialmente a TV, vêm provocando. A questão é abordada por Ianni (1996), segundo quem, a experiência de contato na agricultura produz sujeitos diferenciados.

Os sujeitos sociais que experienciam o rural produzem a sua vida material com diversas atividades além da agricultura (inclusive serviços $e$ indústrias reconhecidas como atividades da cidade). Suas vivências significantes cotidianas [...] expressam elementos culturais de relações com a natureza e a própria vida (Ianni, 1996:297).

Santos (2002) afirma que com a intensificação das dimensões econômicas e políticas globalizadas, as relações sociais tendem a pressionar as fronteiras dos antigos localismos da tradição, da linguagem e da ideologia gerando, assim, formas de relações sociais mais globalizadas. Veiga (2004) e Moreira (2005) também enfatizam a necessidade de compreender as identidades rurais contemporâneas a partir de processos de globalização, 
pouco restando da dualidade entre o rural e o urbano como polos divergentes. É essa a situação que para nós se apresentou: uma mescla de urbano e rural no jeito de viver dessas mulheres. Importante ainda lembrar que o Município de Imigrante se emancipou em 1988, constituindo-se de áreas territoriais antes pertencentes a outros dois municípios (Estrela e Garibaldi) e que parte do que hoje é perímetro urbano de Imigrante era até então área rural. Assim, o território urbano ainda apresenta muitas características do rural.

\section{Conclusão e reflexões finais}

A apreensão das construções subjetivas das mulheres acerca de si mesmas, do significado de sua participação na rede social clube de mães; a compreensão de suas inseguranças; a descoberta de suas referências para os desafios do dia-a-dia na vida familiar, no trabalho, enfim, no contexto social inspiraram este trabalho de pesquisa participante com viés antropológico.

A partir das primeiras aproximações de convivência e das observações de seu comportamento em diferentes momentos $e$ espaços, percebemos claramente a manifestação de diferentes identidades. $\mathrm{E}$, paralelamente a isso, nos rituais comuns de encontros, por exemplo, a linguagem utilizada nas conversações, os comportamentos frente às situações, entre outros aspectos, demonstraram aspectos culturais comuns servindo de referência ou de ancoragem, conforme referido por Santos (2000) para as construções e adaptações de significado das mulheres pesquisadas.

Os resultados se assemelham ao que Berto (2004) e Deere (2002) constataram nos seus trabalhos que afirmam a importância da atuação das mulheres em grupos de base de mulheres, com vistas à promoção de justiça social. Com organização e liderança, as mulheres têm feito diferença no que concerne ao resgate da arte e da cultura, da educação alternativa, da autoestima e, por tudo isso, da cidadania. Recente estudo etnográfico de Plastino (2006) sobre dança de salão no Rio de Janeiro apontou 
interessantes construções e reconstruções identitárias de sujeitos idosos, homens e mulheres, a partir da interação pela dança. No espaço local, no ambiente conhecido, com a trama da confiança que promove a liberdade de expressão, as identidades se manifestam mais claramente. É perceptível que o autorizar-se a ser, o permitir-se agir, o manifestar-se acerca da vida e dos projetos do grupo acontecem a partir do momento em que a pessoa se autopercebe pertencente ao grupo e por ele se sente credenciada. Bauman (2001) chama de mundo líquido essa fluidez de conhecimentos, valores, pressupostos, verdades. A dinamicidade das coisas, a improbabilidade dos dias, a constante incerteza e medo, características dos tempos modernos, ocasionam a fragmentação do ser, que convive diariamente com múltiplas angústias e medos. As pessoas, nesse contexto, se constroem de forma cada vez mais multifacetadas. Assumem identidades diferenciadas em situações de vida diferentes, buscando se afirmar, o que Hall (2004) define como "crise de identidade". Não é incomum na vida familiar a pessoa agir de forma aberta, expansiva, extrovertida, autoritária, e profissionalmente, como funcionária de uma empresa, ser fechada, introvertida e submissa. Também o inverso pode acontecer e outras variações são possíveis. E nem por isso, trata-se de identidades contraditórias, como era nossa percepção inicial. Somos seres multifacetados, nos adaptamos às múltiplas situações que a vida moderna nos oferece.

Dentro do espaço investigado, percebemos que há uma identificação interessante entre as mulheres: fortes laços de família; intensa relação de cuidado com a terra, com os animais e com as plantas; valores culturais preservados desde os colonizadores do local (presentes no cotidiano e nem sempre percebidos, situação já apontada por Cuche [2004] em seus estudos); atribuição de relevante importância à educação e a socializar novas aprendizagens, experiências, afetos.

Os sentimentos relacionados à experiência da maternidade servem de pano de fundo para as costuras que amenizam conflitos 
e oportunizam entendimentos. É o que Boff (2004) chama de inteireza da experiência feminina e faz uma interessante analogia com a maternidade da terra, que acolhe a semente, a acalenta, alimenta-a e faz produzir. É muito intensa a ligação dessas mulheres com a terra, o cultivo e seus cuidados.

A necessidade de ter com quem conversar e a satisfação de produzir coisas (por isso, a importância dos trabalhos artesanais) são aspectos preponderantes no significado da existência do grupo. Sennet (2009), retomando a obra de Arendt, nos auxilia nesse entendimento: "[...] as pessoas que trabalham juntas certamente conversam a respeito do que estão fazendo. [...] o pensamento e o sentimento estão contidos no processo de fazer." (Arendt apud Sennet, 2009:17). E esses rituais cotidianos estabelecem a coesão social entre as pessoas.

O trabalho manual artesanal não prescinde do pensar criativo, do ousar fazer e muitas vezes desfazer; esse processo envolve emoção e razão. A construção da obra é a construção do ser, ou sua reconstrução. A alternância da ação e da pausa para avaliar, replanejar, refazer proporciona o desenvolvimento de habilidades manuais, emocionais e de raciocínio. As mulheres constroem a si mesmas, elaboram seus pensamentos $e$ sentimentos, enquanto conversam e realizam com cuidado $e$ paciência, ponto após ponto, dobra após dobra ou nos retoques de pintura e de colagens de suas obras artesanais, nas quais também incluímos as fabricações culinárias e de infusões $e$ pomadas com plantas medicinais.

Elas se afirmam capazes, úteis, importantes na sua condição humana, por meio de suas criações, por isso sua sede por novos conhecimentos, sua abertura para novas práticas. E a percepção de ser capaz de fazer coisas oportuniza melhoria nas relações de grupo. À medida que se ampliam as habilidades criativas dessas mulheres, o que se observou na evolução dos trabalhos - em que não há apenas a repetição de técnicas construtivas, mas surge a ousadia de uma pitada de gosto pessoal -, foi o surgimento de uma "identidade autoral" nas fabricações. A partir de mesmas 
práticas, de mesmos materiais, de mesmas receitas, vão surgindo diferentes construções e o grupo as identificam: "esse ponto de crochê é da C.", "essa caixinha é da M.".

A literatura referente a vida moderna e a globalização nos auxiliou no entendimento das incertezas $e$ inseguranças da vida atual. Compreendemos as recorrentes referências das mulheres à importância dos encontros para conversar, amenizar suas angústias e ampliar entendimentos acerca, inclusive, dos problemas que seu estágio de vida apresenta, pois segundo as percepções individuais e coletivas, mulheres com idade entre $46 \mathrm{e}$ 84 anos de idade apresentam dificuldades no seu processo de envelhecimento, porque precisam manter-se produtivas para sentirem-se valorizadas.

Nós nos humanizamos a partir da linguagem e da vida em grupo, nos afirmamos em nossa identidade, justamente no convívio com os demais, que nunca são iguais, mas a quem precisamos acolher e com quem queremos contribuir.

Desejamos que a contribuição deste trabalho seja no sentido de estimular cada vez mais estudos voltados às ações cotidianas, de pessoas e grupos que anonimamente contribuem para a qualidade de vida planetária, a partir de seu espaço local. A qualificação das relações humanas é ponto crucial nos projetos de desenvolvimento de uma comunidade ou região. $\mathrm{E} O$ entendimento das percepções e significações das pessoas, nas suas ações cotidianas, é ponto de partida para a construção de projetos coletivos. Bandeira (1999), Putnam (1996) e Boisier (1995 e 2002) enfatizam a tese do desenvolvimento de um território como resultado de capital social historicamente construído, democraticamente planejado e mantido pela percepção comum de forte sentimento de pertinência entre seus habitantes que "apesar das diferenças e divergências que possam ter, também têm fortes afinidades e muitos interesses em comum" (Bandeira, 1999:29). E nesse aspecto, certamente o grupo tem muito a avançar, porque há sim, relações conflituosas prolongadas, que representam tensões nocivas ao sistema. 
Investigar as construções subjetivas das mulheres acerca de si mesmas, do significado de sua participação nessa rede social, compreender suas inseguranças e, paralelamente, conhecer suas referências para os desafios do dia-a-dia na vida familiar, no trabalho, enfim, no contexto social inspiraram este trabalho.

A percepção acerca desses sujeitos aponta que o grupo promove a manifestação e a construção de diferentes identidades. $\mathrm{E}$, paralelamente a isso, nos rituais comuns de encontros, por exemplo, a linguagem utilizada nas conversações, os comportamentos frente às situações, entre outros aspectos, demonstram aspectos culturais importantes servindo de referência àquelas mulheres. Retomando Leff (2001), apontamos que nesse grupo se concretiza, a partir do compartilhamento de práticas e do sentimento de familiaridade entre os envolvidos, a sinergia positiva do pertencimento $e$ da solidariedade.

É no nível local que se forjam as identidades culturais, que se expressam como valorização social dos recursos econômicos e como estratégias para a reaproximação da natureza. Se a globalização é o espaço onde as sinergias negativas tornam manifestos os limites do crescimento, o local é o espaço onde emergem as sinergias positivas da racionalidade ambiental. O local "[...] é o espaço onde se articulam identidades culturais $e$ potencialidades ecológicas" (Leff, 2001:340).

A familiaridade de linguagem, rotinas e fazeres comuns, apreensões de significados culturalmente construídos, relações de confiança, tudo conspira a favor do ser-sujeito; ele se mostra, opina, age, se constitui e se reconstrói, elaborando suas angústias, inseguranças e seus desejos.

\section{Referências bibliográficas}

ARENDT, H. A condição humana. Rio de Janeiro, Forense Universitária, 2007.

BANDEIRA, P. Participação, articulação de atores sociais $e$ desenvolvimento regional. Brasilia, IPEA, 1999. 
BARTH, F. Grupos Étnicos e suas fronteiras. In: PoutignAt, P. Teorias da etnicidade. São Paulo, UNESP, 1998.

BAUMAN, Z. Modernidade Líquida. Rio de Janeiro, Jorge Zahar Ed., 2001. Ed., 2009.

Medo e Confiança na Cidade. Rio de Janeiro, Jorge Zahar

BERTO, V. F. Amélia é quem era mulher de verdade? Um estudo acerca das relações de gênero, representações e violência simbólica no cotidiano das comunidades de bairro de Marília, SP (1980-2004). São Paulo, UNESP, 2006.

Boff, L. Saber Cuidar: ética do humano - compaixão pela terra. Petrópolis, Rio de Janeiro, Vozes, 1999.

. Ecologia: grito da terra, grito dos pobres. Rio de Janeiro, Sextante, 2004.

BOISIER, S. El difícil arte de hacer Región. Las regiones como actores territoriales del nuevo orden internacional (Conceptos, problemas y métodos). Peru, Centro de Estudios Regionales Andinos "Bartolomé de las Casas", 1992.

. Hay espacio para el desarollo local in globalizacion? Revista da Cepal, $2005 . \quad$ Disponível em: http://www.eclac.org/publicaciones/xml/1/22211/G2282eBoisier.pdf.

Bourdieu, P. Escritos de Educação. Rio de Janeiro, Editora Vozes, 1998. Zouk, 2007.

A Distinção: Crítica Social do Julgamento. Porto Alegre,

BosI, A. Cultura como Tradição. Cultura Brasileira: Tradição/Contradição. Rio de Janeiro, Jorge Zahar/Funarte, 1987.

BRASIL. Secretaria de Ensino Fundamental. Parâmetros curriculares nacionais. Meio Ambiente e Saúde. Ministério da Educação, 1997.

BRIGGS, J; PeAT, D. A. Sabedoria do Caos: Sete Lições que vão mudar a sua Vida. Rio de Janeiro, Campus, 2000.

CAPRA, F. A teia da vida: uma nova compreensão científica dos sistemas vivos. São Paulo, Cultrix, 2006. 
Identidade e pertencimento

CARVAlHo, I. C. M. A invenção do sujeito ecológico: identidade e Subjetividade na Formação de Educadores Ambientais. Porto Alegre, Artmed, 2005.

CarvalHo, J. M. Cidadania no Brasil: O longo caminho. Rio de Janeiro, RJ, Civilização Brasileira, 2004.

CASTRO, L. R. Aventura urbana. Rio de Janeiro, 7 Letras, 2004.

CuCHE, D. A noção de cultura nas ciências sociais. Bauru, SP, EDUSC, 2002.

DEERE, C. D. O empoderamento da mulher: direitos à terra e direitos de propriedade na América Latina. Porto Alegre, Editora da UFRGS, 2002.

FASSINI, E. Identidade individual e coletiva: percepções e representações das mulheres na sua participação em um Clube de Mães no Rio Grande do Sul. Dissertação de Mestrado, Centro Universitário UNIVATES, Lajeado, 2010.

FiNO, C. N. A Etnografia enquanto método: um modo de entender as culturas (escolares) locais. Portugal, Universidade da Madeira, 2007. Disponível em: http://www3.uma.pt/carlosfino/publicacoes/22.pdf.

GadAmeR, H. J. Verdade e método. Petrópolis, RJ, Vozes, 1998.

GeERTZ, C. A interpretação das culturas. Rio de Janeiro, Guanabarra Koogan, 1989.

GIL, A. C. Como elaborar projetos de pesquisa. São Paulo, Atlas, 2006.

HABERMAS, J. Conhecimento e Interesse. Benjamin, W.; HoRKHEIMER, M.; Adorno, T. W.; Habermas, J. Os Pensadores. São Paulo, Abril Cultural, 1980.

. O discurso filosófico da modernidade: doze lições. São Paulo, Martins Fontes, 2000.

HALL, S. A identidade cultural na pós modernidade. Rio de Janeiro, DP\&A, 2004.

HESSEL, L. Município de Imigrante - Registros e Memórias. Porto Alegre, Edições EST, 1998. 
IANNI, O. A Era do Globalismo. Rio de Janeiro, Civilização Brasileira, 1996.

LEFF, E. Saber ambiental: sustentabilidade, racionalidade, complexidade, poder. Petrópolis, Ed. Vozes, 2001.

MaiA, G. F., Perurena, F. C. V. Corpo, Velhice e Saúde: formas de viver $e$ ser na velhice. Fazendo gênero 8, corpo violência e poder. Florianópolis, UFSC, 2008. Disponível em: http://www.fazendogenero.ufsc.br/8/sts/ST47/Maia-Perurena_47.pdf. Acesso em: dez 2009.

Minayo, M. C. S.; CoImBrA, C. E. A. Antropologia, Saúde e Envelhecimento. Rio de Janeiro, Editora Fiocruz, 2001.

MinAYO, M. C. S. O desafio do conhecimento: pesquisa qualitativa em saúde. São Paulo, HUCITEC, 2004.

MINISTÉRIO DA EDUCAÇÃO. Cultura popular e educação. Salto para o futuro. Brasília, 2008.

MoraEs, R. Análise de Conteúdo. Revista Educação vol. 22, n 37, Porto Alegre, 1999, pp.7-32.

MORIN, E. Os sete saberes necessários à educação do futuro. São Paulo, Cortez, 2001.

- A Cabeça bem-feita: repensar a reforma, reformar o pensamento. Rio de Janeiro, Bertrand Brasil, 2009.

MoscovicI, S. Representações sociais: investigação em psicologia social. Petrópolis, Vozes, 2004.

Neves, V. F. A. Pesquisa-Ação e Etnografia: caminhos cruzados. Pesquisas e Práticas Psicossociais, v.1, São João Del-Rei, MG, 2006.

PÉREZ, B. C. et al. Cidadania e participação social: um estudo com crianças no Rio de Janeiro. Psicologia \& Sociedade vol. 20, $n^{\circ} 2$, Rio de Janeiro, UFRJ, 2008, pp.181-191.

PlastinO, V. V. Dança com Hora Marcada: uma etnografia da atração social em bailes de salão no Rio de Janeiro. Rio de Janeiro, UFRJ, 2006.

PutnAm, R. D. Comunidade e Democracia: a experiência da Itália moderna. Rio de Janeiro, Editora da Fundação Getúlio Vargas, 1996. 
Identidade e pertencimento

SACHS, I. Sociedade, Cultura e Meio Ambiente. Mundo \& Vida, vol. 2, ano 1, 2000, pp.7-13.

SANTOS, M. F. S. Representação social e identidade. In: MOREIRA, A. S. P.; OliveIRA, D. C. (Orgs.) Estudos Interdisciplinares de Representações Sociais. Goiânia, Edições AB, 1998, pp.151-159.

SANTOS, B. S. Um discurso sobre as ciências. Porto, Portugal, Edições Afrontamento, 1987.

. Globalização: fatalidade ou utopia? Porto, Portugal, Edições Afrontamento: 2001.

. Para um novo senso comum: a ciência, o direito e a política na transição paradigmáticaSão Paulo, Cortez, 2001.

. Pela mão de Alice: o social e o político na pós modernidade. São Paulo, Cortez, 2001.

. A globalização e as ciências sociais. São Paulo, Cortez, 2002.

. O Fórum Social Mundial: manual de uso. São Paulo, Cortez Editora, 2005.

. Renovar a teoria crítica ou reinventar a emancipação social. São Paulo, Boitempo, 2007.

SENNETt, R. O Artífice. Rio de Janeiro, Record, 2009.

SiLVA, R. M. C. (Org). Cultura Popular e Educação. Brasília, Salto para o Futuro, 2008.

SILVEIRA, A. C. M; RONSINI, V. M. Representação e Identidade: três estudos em comunicação. Santa Maria, RS, FACOS-FIPE-UFSM, 2001.

SOFFIATI, A. Fundamentos filosóficos e históricos para o exercício da ecocidadania e ecoeducação. In: LOUREIRO, Carlos F. B, LAYRARGUES Philipe P. e CASTRO, Ronaldo S. (orgs). Educação ambiental repensando o espaço da cidadania. São Paulo, Cortez, 2005, pp.23-67.

ThOMPSON, P. A voz do passado: história oral. Rio de Janeiro, Paz e Terra. 1998.

VEIGA, J. E. Destinos da ruralidade no processo de globalização. Estudos Avançados, vol. 18, n 51, São Paulo, 2004, pp.51-67. 
VILlasante, T. R.; GaRRIDO, F. G. Reflexividades sócio-praxicas: esquemas metodológicos participativos. In: VILLASANTE, T. R.; GARRIDO, F. G. Metodologías y Presupuestos Participativos, Madri, Iepala Editorial, 2002, pp.43-76.

VILlasante, T. R. Redes e Alternativas - Estratégias e estilos criativos na complexidade social. Petrópolis, Vozes, 2002. 